\title{
Counting on chemistry: laboratory evaluation of seed-material-dependent detection efficiencies of ultrafine condensation particle counters
}

\author{
Peter Josef Wlasits ${ }^{1}$, Dominik Stolzenburg ${ }^{1,2}$, Christian Tauber ${ }^{1}$, Sophia Brilke ${ }^{1}$, Sebastian Harald Schmitt ${ }^{3}$, \\ Paul Martin Winkler ${ }^{1}$, and Daniela Wimmer ${ }^{1}$ \\ ${ }^{1}$ University of Vienna, Aerosol Physics and Environmental Physics, Boltzmanngasse 5, 1090 Vienna, Austria \\ ${ }^{2}$ University of Helsinki, Institute for Atmospheric and Earth System Research/Physics, 00014 Helsinki, Finland \\ ${ }^{3}$ TSI GmbH, Neukoellner Straße 4, 52068 Aachen, Germany
}

Correspondence: Paul Martin Winkler (paul.winkler@univie.ac.at)

Received: 17 December 2019 - Discussion started: 18 February 2020

Revised: 13 May 2020 - Accepted: 27 May 2020 - Published: 13 July 2020

\begin{abstract}
Condensation particle counters (CPCs) are crucial instruments for detecting sub-10 $\mathrm{nm}$ aerosol particles. Understanding the detection performance of a CPC requires thorough characterization under well-controlled laboratory conditions. Besides the size of the seed particles, chemical interactions between the working fluid and the seed particles also influence the activation efficiencies. However, common seed particle materials used for CPC characterizations are not chosen with respect to chemical interactions with vapor molecules of the working fluid by default. Here, we present experiments on the influence of the seed particle material on the detection efficiencies and the $50 \%$ cutoff diameters of commonly used CPCs for the detection of sub- $10 \mathrm{~nm}$ particles. A remarkable set consisting of six different and commercially available particle detectors, including the newly developed TSI V-WCPC 3789 and a tuned TSI 3776, was tested. The corresponding working fluids of the instruments are $n$-butanol, diethylene glycol and water. Among other materials we were able to measure detection efficiencies with nanometer-sized organic seed particles reproducibly generated by the oxidation of $\beta$-caryophyllene vapor in a flow tube. Theoretical simulations of supersaturation profiles in the condensers were successfully related to measured detection efficiencies. Our results demonstrate the importance of chemical similarities between seed particles and the working fluids used when CPCs are characterized. We anticipate our study to contribute to a deeper understanding of chemical interactions during heterogeneous nucleation processes.
\end{abstract}

\section{Introduction}

Ultrafine aerosol particles ( $<100 \mathrm{~nm}$ ) might cause severe effects on human health (Pedata et al., 2015) and impact the global climate through the aerosol indirect effect (Bauer and Menon, 2012; Albrecht, 1989). In the atmosphere, aerosol particles have primary and secondary sources. Secondary particles form when gaseous precursors oxidize to lowvolatility compounds, which at high enough abundances can form molecular clusters. Clusters grow by condensation into the nucleation- and Aitken-mode size range and eventually reach sizes at which they can act as cloud condensation nuclei (CCN). A detailed understanding of the mechanisms leading to aerosol formation and growth, i.e., new particle formation (NPF; Nieminen et al., 2018), requires the careful measurement of particles in the cluster-particle transition and nucleation-mode size regime. Quantitative measurements of aerosol particles in the size range $1-10 \mathrm{~nm}$ remain a major challenge for the understanding of the mechanisms responsible for NPF.

Condensation particle counters (CPCs), which optically detect nanometer-sized particles after condensational growth, are state-of-the art instruments for particle measurements in the sub-10 $\mathrm{nm}$ size regime. Since the introduction of Aitken's "dust counter" towards the end of the 19th century (Aitken, 1888), particle counters capable of detecting smaller and smaller aerosol particles have been developed (Stolzenburg and McMurry, 1991; Seto et al., 1997; GameroCastaño and Fernández de la Mora, 2000; McMurry, 2000; 
Sgro and Fernández de la Mora, 2004; Vanhanen et al., 2011; Kangasluoma and Attoui, 2019). Thus, CPCs are used in many different fields, including atmospheric studies (Brilke et al., 2020a), the characterization of combustion processes (Giechaskiel et al., 2009), monitoring occupational health hazards (Gao et al., 2019) and clean-room monitoring systems (Ahonen et al., 2017).

CPCs are based on two fundamental processes: heterogeneous nucleation and subsequent condensational growth. The seed particles are mixed with a condensable vapor, followed by a rapid temperature change, leading to vapor supersaturation, particle activation by heterogeneous nucleation and subsequent condensational growth. The seed particles grow to sizes large enough that they can be detected optically. This process can be achieved by different working fluids such as $n$-butanol, water or diethylene glycol (DEG), which are commonly used in commercial instruments. Previous research has shown that the molecular weight and the surface tension of the working fluid have an impact on particle activation (Iida et al., 2009; Magnusson et al., 2003). Higher molecular weights and higher surface tensions allow for the activation of smaller particles.

The detection performance of CPCs is commonly quantified by the $50 \%$ cutoff diameter $\left(d_{\mathrm{p}, 50}\right)$. The total detection efficiency of a CPC, $\eta_{\text {tot }}\left(d_{\mathrm{p}}\right)$, is given by the following relation (Stolzenburg and McMurry, 1991):

$\eta_{\text {tot }}\left(d_{\mathrm{p}}\right)=\eta_{\mathrm{s}}\left(d_{\mathrm{p}}\right) \cdot \eta_{\mathrm{a}}\left(d_{\mathrm{p}}\right) \cdot \eta_{\mathrm{d}}\left(d_{\mathrm{p}}\right)$.

Here, $\eta_{\mathrm{s}}\left(d_{\mathrm{p}}\right)$ is the sampling efficiency accounting for the particle losses inside the instrument. $\eta_{\mathrm{a}}\left(d_{\mathrm{p}}\right)$ corresponds to the activation efficiency of the seed particles by heterogeneous nucleation, and $\eta_{\mathrm{d}}\left(d_{\mathrm{p}}\right)$ is the detection efficiency of the particles in the optical system.

Heterogeneous nucleation processes are influenced by the physicochemical properties of the seed particles. If the seed particle is entirely soluble in the condensing liquid, Köhler theory (Köhler, 1936) can describe the activation behavior. If the seed is insoluble, heterogeneous nucleation theory (Fletcher, 1958) is applicable. Other relevant seed particle properties for their activation are size, shape, wettability and charging state (Kupc et al., 2013b). Previous studies have shown that the charging state of the seed particles might also have an influence on their respective detection efficiencies (Kangasluoma et al., 2016; Winkler et al., 2008). Chemical processes on the molecular level mediate particle activation, including interactions related to the chemical composition of the seed particles and the molecules of the working fluids (Tauber et al., 2019a; Kangasluoma et al., 2016; Petäjä et al., 2006). Previous research has identified potential molecular characteristics that act as docking stations to the seed particle. These docking stations are polar groups, like $-\mathrm{OH}$ ( $\mathrm{Li}$ and Hogan, 2017). The distribution of polar groups, in general, defines the chemical polarity of a vapor molecule. A table summarizing the relevant physical properties of the working fluids can be found in the Supplement
(Table S1). Furthermore, it has been shown that the activation probability is influenced by the supersaturation occurring in the condenser of the CPC and the working fluid used (Iida et al., 2009; Wimmer et al., 2013). As a result the combination of CPCs based on different working fluids might even provide information concerning the chemical composition of the seed particles by showing differing detection efficiencies (Kulmala et al., 2007; Kangasluoma et al., 2014). Additionally, previous studies have shown that the detection efficiency of CPCs for sub- $2 \mathrm{~nm}$ particles can be improved by tuning the instrument settings (Barmpounis et al., 2017; Attoui, 2018).

Here we present the results of studying the effect of the working fluid on the activation efficiencies with respect to various seed particle compositions. The broad array of investigated particle detectors was composed of $n$-butanol-based CPCs (TSI 3772, TSI 3776 and Airmodus A20), water-based CPCs (TSI 3788 and V-WCPC 3789) and a DEG-based booster stage (TSI 3777). The experiments have been performed under reproducible laboratory conditions and provide further insights into particle activation in CPCs.

\section{Experimental methods}

A schematic of the experimental setup is displayed in Fig. 1. The counting efficiencies of the CPCs were measured using four different types of seed particles generated from sodium chloride $(\mathrm{NaCl}$, pro analysi, Merck $\mathrm{KGaA}$, Darmstadt, Germany), silver (Ag, wool for elemental analysis, CAS no.: 7440-22-4, Merck KGaA, Darmstadt, Germany), ammonium sulfate $\left(\left(\mathrm{NH}_{4}\right)_{2} \mathrm{SO}_{4}\right.$, pro analysi, Merck KGaA, Darmstadt, Germany) and $\beta$-caryophyllene $\left(\mathrm{C}_{15} \mathrm{H}_{24}, \mathrm{BCY}\right.$, $\geq 80 \%$, CAS no.: 87-44-5, Sigma Aldrich, St. Louis, USA). To avoid a possible influence of the relative humidity of the carrier gas on the detection efficiency (Tauber et al., 2019a; Kangasluoma et al., 2016), synthetic air (ALPHAGAZ 1 Air, $99.999 \%$ (5.0), $\mathrm{H}_{2} \mathrm{O}<3.0 \mathrm{ppm} \mathrm{mol}^{-1}$, Air Liquide) was used as a carrier gas and the aerosol was generated in dry conditions in all measurements. Sodium chloride, silver and ammonium sulfate particles were produced in a tube furnace (Scheibel and Porstendorfer, 1983) manufactured by Carbolite Gero GmbH \& Co. KG, Germany. The particle material is put onto a crucible and inserted into the cylindrical furnace. The material evaporates in the heated furnace, and rapid cooling downstream of the heated section leads to particle formation. Table S2 contains the approximate furnace temperatures for different seed particle materials.

Subsequent to the aerosol generator, a dilution flow of synthetic air is joined with the aerosol flow. A soft X-ray charger (TSI 3088 Advanced Aerosol Neutralizer) is used to achieve a steady-state charge distribution for the analyzed aerosol flow. In the next step, the aerosol enters a custommade Vienna-type differential mobility analyzer (DMA, as presented in Winkler et al., 2008, and referred to as nanoDMA; see the Supplement), where particles are selected ac- 

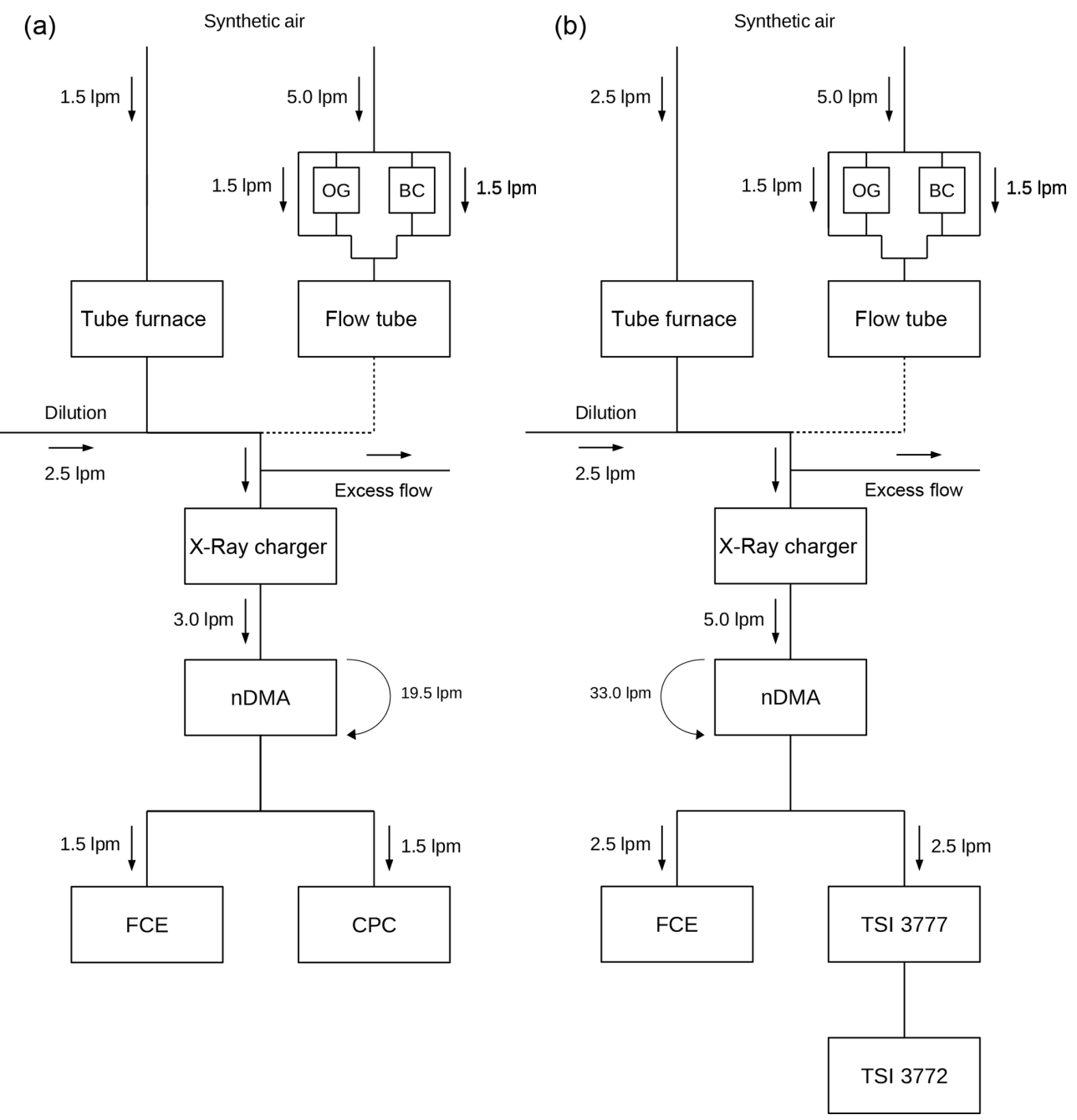

Figure 1. Schematic of the experimental setup: the figure shows a schematic of the experimental setup that was used to measure the detection efficiency of the ultrafine particle counters. A Faraday cup electrometer was used as a reference. $\mathrm{C}_{15} \mathrm{H}_{24} \mathrm{O}_{x}$ seeds were generated using BCY (BC), an ozone generator (OG) and a flow tube. The curved arrows mark the sheath air cycle. Panel (a) shows the setup for the measurements involving just CPCs. Due to the higher aerosol inlet flow rate of the TSI 3777 the setup was modified (b).

cording to their electrical mobility. The electrical mobility diameters of the selected particles range between 1 and $25 \mathrm{~nm}$. According to Flagan (1999), the flow rate ratio $\delta$ defines the limiting resolution in the absence of diffusion when the DMA flows are balanced and is given by the sum of the aerosol inlet flow $Q_{\mathrm{a}}$ and the sample outlet flow $Q_{\mathrm{s}}$ divided by the sum of the sheath flow rate $Q_{\text {sh }}$ and the excess flow rate $Q_{\mathrm{e}}$ :

$\delta=\frac{Q_{\mathrm{a}}+Q_{\mathrm{s}}}{Q_{\mathrm{sh}}+Q_{\mathrm{e}}}$.

The limiting resolution throughout our experiments is therefore approximated by 0.15 . It is important to note that in the 1-2 nm size range diffusional broadening can degrade the DMA resolution (Jiang et al., 2011). The selected aerosol might be polydisperse and the selected particle diameter must be seen as an average diameter with an envelope (see Fig. S1). In our study this envelope is given by $\pm 0.5 \mathrm{~nm}$ based on a maximum uncertainty approximation by taking into account the results of Reischl et al. (1997). The diffusional broadening of the transfer function of the nano-DMA between 1 and $5 \mathrm{~nm}$ was also presented by Winkler et al. (2008). In their study the authors calculated a geometric standard deviation of approximately 1.07 for a size-classified output aerosol composed of particles with a mean diameter of $1 \mathrm{~nm}$. By applying positive voltage to the nano-DMA, particles with negative charge were selected. Negatively charged particles of the same composition are assumed to achieve higher activation efficiencies at small sizes independently of the CPCs used (Kangasluoma et al., 2016; Winkler et al., 2008) and are thus preferred for applications in size distribution measurements down to particles as small as $1 \mathrm{~nm}$. Previous studies on the counting efficiency of CPCs involving sub-2 $\mathrm{nm}$ particles were conducted using high-resolution 
DMAs (Attoui and Kangasluoma, 2019). In order to assess the suitability of the nano-DMA used for seed particles with diameters smaller than $2 \mathrm{~nm}$, previous measurements of negatively charged $\mathrm{Ag}$ and $\mathrm{NaCl}$ seeds using a tuned TSI 3776, the TSI 3777 and a high-resolution DMA (UDMA) (Steiner et al., 2010) were used. Parts of the results and the experimental setup used were published by Brilke et al. (2020b). The results of the comparison are displayed in the Supplement.

A flow unit, including a total particle filter and a silica gel dryer, maintains a sheath airflow rate of $19.5 \mathrm{~L} \mathrm{~min}^{-1}$ (see Fig. 1a) or $33.0 \mathrm{~L} \mathrm{~min}^{-1}$ (see Fig. 1b), respectively, in the DMA. The silica gel was exchanged frequently in order to maintain a dry sheath air cycle (closed-loop system). Downstream of the DMA the aerosol is evenly distributed among a CPC and a Faraday cup electrometer (TSI 3068B Aerosol Electrometer) using a $\mathrm{T}$ junction. The flow rates were adjusted and monitored using a TSI 4140 mass flowmeter. For the measurements with the DEG-based booster stage, a different flow setup was used due to the higher inlet flow rate of the instrument (see Fig. 1b). Accordingly, the tube furnace was operated with $2.5 \mathrm{~L} \mathrm{~min}^{-1}$ of synthetic air and the aerosol inlet flow of the nano-DMA was increased to 5.0 $\mathrm{L} \mathrm{min}^{-1}$. Consequently, the setup used for the generation of seed particles based on $\mathrm{NaCl}, \mathrm{Ag}$ and $\left(\mathrm{NH}_{4}\right)_{2} \mathrm{SO}_{4}$ bears a close resemblance to the setup described in Kangasluoma et al. (2013), wherein the authors also present mass spectra of furnace-generated clusters. The study by Kangasluoma et al. (2013) can be used to infer the chemical composition of some of the seed particles used in this study.

Particles consisting of oxidized $\beta$-caryophyllene $\left(\mathrm{C}_{15} \mathrm{H}_{24} \mathrm{O}_{x}, \mathrm{BCYO}_{x}\right)$ were produced in a flow tube (Hearn and Smith, 2006). The seeds were produced by evaporating $\mathrm{BCY}$ into a clean airstream and subsequently mixing it with ozone, allowing the ozonolysis reaction to take place inside the flow tube. Ozone was generated using a custom-made ultraviolet (UV) lamp with adjustable intensity. An intensity-ozone calibration was performed prior to the experiments with an ozone monitor (ThermoFisher Scientific, model i49), suggesting that the ozone concentrations were in the range of $100-500 \mathrm{ppb}$. The mode diameter of the resulting size distribution can be shifted by varying the length of the reaction path of the flow tube using an adjustable piston and thus the reaction time of the organic compounds. The diameter of the flow tube used was $0.05 \mathrm{~m}$, and the length of the reaction path was varied between 0.1 and $0.4 \mathrm{~m}$. The temperature of the BCY evaporator was kept at $283.15 \mathrm{~K}$.

The CPCs used and the booster stage are presented in Table 1. All particle counters are based on the laminar-flow principle and have $50 \%$ cutoff diameters below $10 \mathrm{~nm}$ according to the manufacturers. Here, it should be noted that the TSI 3789 was operated in the $2 \mathrm{~nm}$ mode for all experiments. The $2 \mathrm{~nm}$ mode is the default setting by the manufacturer for low-cutoff measurements based on calibrations with
Table 1. Instrumentation used: the table shows the particle counters used, including their model numbers, the working fluids used and the $50 \%$ cutoff diameter as stated by the manufacturers.

\begin{tabular}{lllr}
\hline Manufacturer & Model & Working fluid & $\begin{array}{r}d_{\mathrm{p}, 50} \\
(\mathrm{~nm})\end{array}$ \\
\hline TSI & 3776 & $n$-butanol & 2.5 \\
TSI & 3772 & $n$-butanol & 10.0 \\
TSI & 3788 & water & 2.5 \\
TSI & 3789 & water & 2.2 \\
TSI & 3777 & DEG & 1.4 \\
Airmodus & A20 & $n$-butanol & 7.0 \\
\hline
\end{tabular}

sucrose. The $n$-butanol- and DEG-based instruments implement a typical architecture consisting of a heated saturator and a cooled condenser. In the case of the TSI 3772 and the Airmodus A20 the entire aerosol flow reaches the heated saturator. The TSI 3776 and TSI 3777 are additionally equipped with a capillary regulating the aerosol flow (Stolzenburg and McMurry, 1991). This capillary-sheath layout helps to keep the aerosol flow centered and enhances the detection efficiency by achieving a higher and sharper supersaturation profile within the condenser and reducing diffusional losses (Stolzenburg and McMurry, 1991). In the case of the waterbased TSI 3788 a cooler conditioner is followed by a heated growth tube (Hering et al., 2005). Here, the aerosol flow is first cooled and then enters a heated region of supersaturated vapor. The temperatures of the sections have to be switched due to the higher diffusion coefficient of water compared to heat transfer. Lastly, the TSI 3789 (V-WCPC 3789) is based on a three-step principle: a cool conditioner, a warm initiator and a cooler moderator (Hering et al., 2017). The moderator is necessary for removing water vapor and heat while maintaining supersaturated conditions (Hering et al., 2019). In contrast to the TSI 3788 , the TSI 3789 is not based on a capillary-sheath layout.

By changing the internal settings of three selected CPCs, the $50 \%$ cutoff diameters were pushed to smaller sizes using $\mathrm{BCYO}_{x}$ particles. In the case of the TSI 3777 and the TSI 3789 , the boosting was achieved by changing the temperature settings. In the case of the tuned TSI 3776 (denoted as TSI $3776^{T}$ ), the internal flows were also adjusted. The valve regulating the sheath airflow is adjusted such that the sample flow rate of the CPC increases to $2.5 \mathrm{~L} \mathrm{~min}^{-1}$ (Barmpounis et al., 2017; Brilke et al., 2020b).

The detection efficiency $\eta$ is determined by comparing the particle number concentration measured by a CPC, $N_{\mathrm{CPC}}$, to the particle number concentration of the Faraday cup electrometer $(\mathrm{FCE}), N_{\mathrm{FCE}}$ :

$\eta=\frac{N_{\mathrm{CPC}}}{N_{\mathrm{FCE}}}$.

After the tube furnace had reached a stable state, the number concentrations were simultaneously measured for $45 \mathrm{~s}$. 
An uncertainty analysis of measurement data was performed according to the rules of Gaussian error propagation.

\section{Results and discussion}

\subsection{Composition-dependent counting efficiencies}

Figure 2 shows the detection efficiencies measured with two CPCs (TSI 3776 and TSI 3789) and the CPC-conditioner combination (TSI 3777 and TSI 3772). The abscissa is kept between 1 and $10 \mathrm{~nm}$ in order to set focus on the differences between the seed particles used. The detection efficiency shows a clear dependence on the seed particle composition and the working fluid. The smallest $50 \%$ cutoff diameters using the DEG-based TSI 3777 were accomplished by using $\mathrm{NaCl}$ and $\left(\mathrm{NH}_{4}\right)_{2} \mathrm{SO}_{4}$ seeds. Both seed particles showed a $50 \%$ cutoff diameter of $1.6 \pm 0.2 \mathrm{~nm}$. In the case of the TSI 3776, $\mathrm{BCYO}_{x}$ seeds were found to have the smallest $50 \%$ cutoff diameter of $2.8 \pm 0.3 \mathrm{~nm}$. Lastly, $\mathrm{NaCl}$ and $\left(\mathrm{NH}_{4}\right)_{2} \mathrm{SO}_{4}$ seeds exhibited the smallest $50 \%$ cutoff diameter using the TSI $3789(2.3 \pm 0.1 \mathrm{~nm})$. Interestingly, the TSI 3777 shows a significant difference between the activation of ionically bound (and polar) salts $(\mathrm{NaCl}$ and $\left.\left(\mathrm{NH}_{4}\right)_{2} \mathrm{SO}_{4}\right)$ and less polar seed particles $\left(\mathrm{Ag}\right.$ and $\left.\mathrm{BCYO}_{x}\right)$ : the polar compounds are activated at smaller diameters compared to the nonpolar ones. In the case of the TSI 3776 the detection efficiency curves are very similar for all seed particles, except for $\mathrm{NaCl}$. The related detection efficiency curve is shifted towards larger diameters. The water-based CPC shows a much smaller $50 \%$ cutoff diameter for $\mathrm{NaCl}$ and ammonium sulfate compared to the butanol-based counter $(2.30 \pm 0.12 \mathrm{~nm}$ vs. $4.08 \pm 0.51 \mathrm{~nm}$ for $\mathrm{NaCl})$. Overall, the difference between the smallest and the largest $50 \%$ cutoff diameter is approximately $1 \mathrm{~nm}$ for all three CPCs.

The measured detection efficiency curves show the following two features: (i) the slopes corresponding to the DEGbased TSI 3777 are steeper compared to the $n$-butanol-based TSI 3776 and the water-based TSI 3789. (ii) The counting efficiency of the TSI 3776 and the TSI 3777 reaches 1 around $10 \mathrm{~nm}$ in both cases. In contrast, the detection efficiency of the TSI 3789 reaches 1 at about $20 \mathrm{~nm}$ (see Figs. S2 and S3).

\subsection{Comparison of the water-based CPCs}

Subsequently, the two investigated water-based CPCs were directly compared to each other. Figure 3 shows a direct comparison of the detection efficiency curves for the two different water-based CPCs (TSI 3788 and TSI 3789). The TSI 3788 shows almost identical curves for $\mathrm{NaCl}$ and ammonium sulfate, with a $50 \%$ cutoff diameter of $2.2 \pm 0.1 \mathrm{~nm}$ for ammonium sulfate, while the curves for the less polar compounds $\left(\mathrm{BCYO}_{x}\right.$ and $\left.\mathrm{Ag}\right)$ are shifted by approximately $1 \mathrm{~nm}$ (see Fig. 3a). The TSI 3789, on the other hand, shows a different kind of compound dependence, since the detection efficiency curves for polar and less polar seeds are not separated as clearly. All $50 \%$ cutoff diameters range from 2.3 to $3.4 \mathrm{~nm}$ and are similar to the cutoff diameters of the TSI 3788, with $\mathrm{NaCl}$ having the lowest $d_{\mathrm{p}}, 50$ and $\mathrm{BCYO}_{x}$ having a rather high $d_{\mathrm{p}, 50}$. The curves measured with the TSI 3788 are steeper compared to the TSI 3789. As shown in Fig. 3c, the lower detection efficiencies for the TSI 3789 below $10 \mathrm{~nm}$ are due to higher internal losses compared to the TSI 3788. This behavior is most probably linked to the fact that the TSI 3789 is not based on a capillary-sheath layout. The upper curve shows the detection efficiency corrected for diffusional losses in the inlet and conditioner according to Gormley and Kennedy (1948) for Ag seeds. The corrected detection efficiency curves of the other seeds are presented in the Supplement (see Fig. S5).

\subsection{Comparison of the $n$-butanol-based CPCs}

Figure 4 shows the direct comparison of the butanol-based CPCs. Three out of the four butanol-based CPCs, i.e., the TSI 3772, the TSI 3776 and the Airmodus A20, show the expected activation pattern: $\mathrm{BCYO}_{x}$ and $\mathrm{Ag}$ seeds are activated at smaller diameters compared to $\left(\mathrm{NH}_{4}\right)_{2} \mathrm{SO}_{4}$ and $\mathrm{NaCl}$ seeds. The Airmodus A20 reaches its plateau at detection efficiency values of about 0.9 at $20 \mathrm{~nm}$.

The TSI $3776^{T}$ barely shows a composition dependence of the $50 \%$ cutoff diameters, thereby confirming the results of Brilke et al. (2020b) for Ag seeds. There is no significant difference between the smallest and the largest $50 \%$ cutoff diameters, which are centered around $2.1 \mathrm{~nm}$. The detection efficiency curves are steep and already reach plateau levels of 1 at $4.5 \mathrm{~nm}$.

\section{$3.450 \%$ cutoff diameters}

Figure 5 summarizes the $50 \%$ cutoff diameters measured with the aforementioned instruments operated at standard settings. The discussed dependence of the detection efficiencies on the working fluids and the seed particle compositions can be seen clearly. The DEG-based TSI 3777 and the two water-based CPCs (TSI 3788 and TSI 3789) show the smallest $50 \%$ cutoff diameters for polar $\mathrm{NaCl}$ and ammonium sulfate seeds. The $n$-butanol-based CPCs activate less polar $\mathrm{BCYO}_{x}$ seeds at the smallest $50 \%$ cutoff diameters. Additionally, our results clearly show that the dependence of the detection efficiency on the seed particle material also influences CPCs with $50 \%$ cutoff diameters larger than $5 \mathrm{~nm}$ as the absolute shifts in the diameters get larger for these models. This applies for the Airmodus A20 and the TSI 3772.

\subsection{Effect of instrument boosting}

As the internal temperature settings in all CPCs used in this work can be adjusted by the customer, a set of experiments was performed to test the instruments with different temperature settings (see Fig. 6). The tests were done using $\mathrm{BCYO}_{x}$ seed particles, and the tested CPCs were the butanol-based 

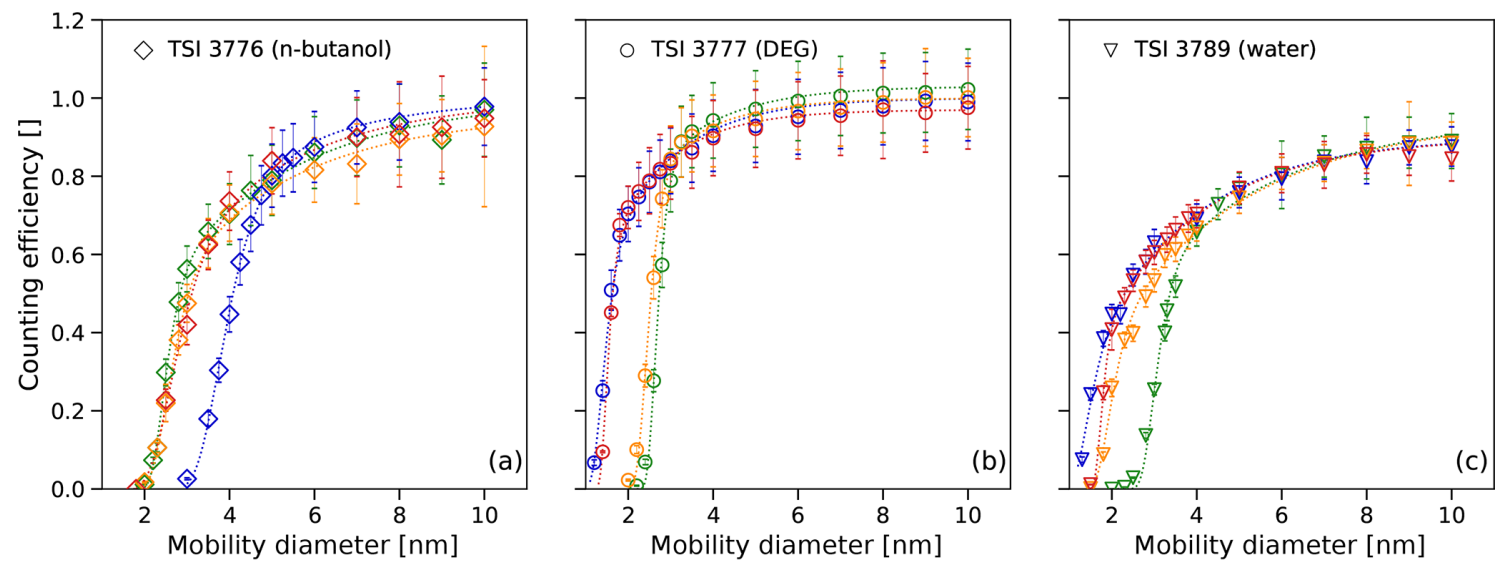

$---\cdot \mathrm{C}_{15} \mathrm{H}_{24} \mathrm{O}_{x}$

----- $\left(\mathrm{NH}_{4}\right)_{2} \mathrm{SO}_{4}$

Ag

$----\cdot \mathrm{NaCl}$

Figure 2. Detection efficiencies and working fluids: the figure shows the detection efficiencies for different seed particle materials as a function of the electrical mobility equivalent diameter. Different colors correspond to different seed particles, and every plot is related to a different working fluid: $n$-butanol (a), DEG (b) and water (c).
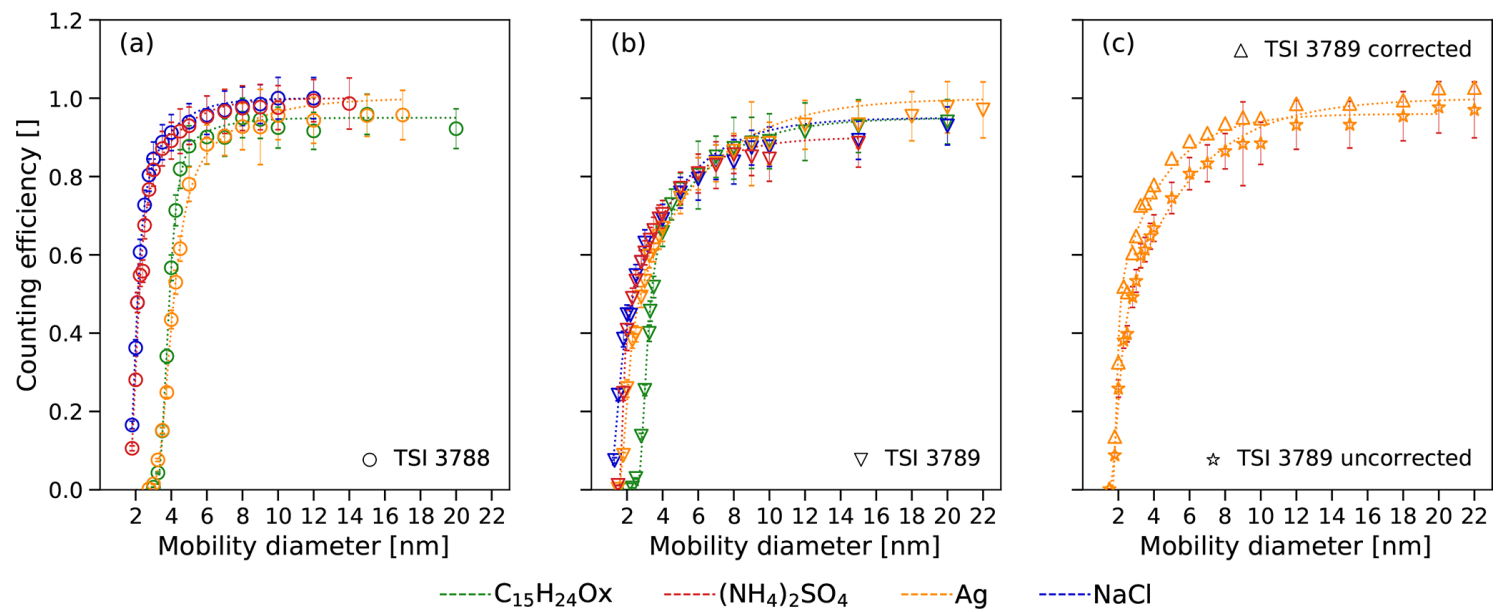

Figure 3. Detection efficiencies of the water-based CPCs: the figure shows the detection efficiencies as a function of the electrical mobility equivalent diameter. Panel (a) corresponds to the TSI 3788, and panel (b) shows the data measured with the TSI 3789. Panel (c) displays the data set for Ag that has been corrected for diffusion losses; panels (a, b) show uncorrected data.

TSI 3776, the DEG-based TSI 3777 and the water-based TSI 3789. In the case of the TSI 3777 and the TSI 3789, only the temperatures were adjusted, and for the TSI 3776 the flows were also changed (TSI $3776^{T}$; see Table 2 for tuned settings). The adjustment of the temperatures did not increase the background count rate of the instruments. The results are shown in Fig. 6. For all tested CPCs, the 50\% cutoff diameters could be reduced (see Table 3 ). The shapes of the curves did not show any significant change except for the TSI $3776^{T}$, which is due to a change in the internal flow rates, leading to reduced diffusion losses at the instrument's inlet. As a result, the overall counting efficiency is enhanced and exhibits a steeper slope. The $50 \%$ cutoff diameter could be lowered by approximately $35 \%$ in the case of the TSI 3776, TSI 3777 and TSI 3789. Figure 6a shows the effect of changing the temperature settings and the inlet flow of the TSI 3776. The effect of just changing the temperature settings is shown in Fig. 6b and c (TSI 3777 and TSI 3789).

\subsection{Discussion of the measurement results}

The results of the performed measurements show that chemical similarities between the seed particle material and the working fluids influence the detection efficiencies of CPCs. As a rule of thumb, compounds of similar chemical structure dissolve more easily. $\mathrm{N}$-butanol is a rather nonpolar fluid and interacts more strongly with particles of nonpolar substances. In contrast, water and DEG are highly polar fluids, and ammonium sulfate and $\mathrm{NaCl}$ are ionic compounds. Therefore, it is expected that ionic compounds such as $\mathrm{NaCl}$ and ammonium sulfate easily dissolve in the polar working fluids and 

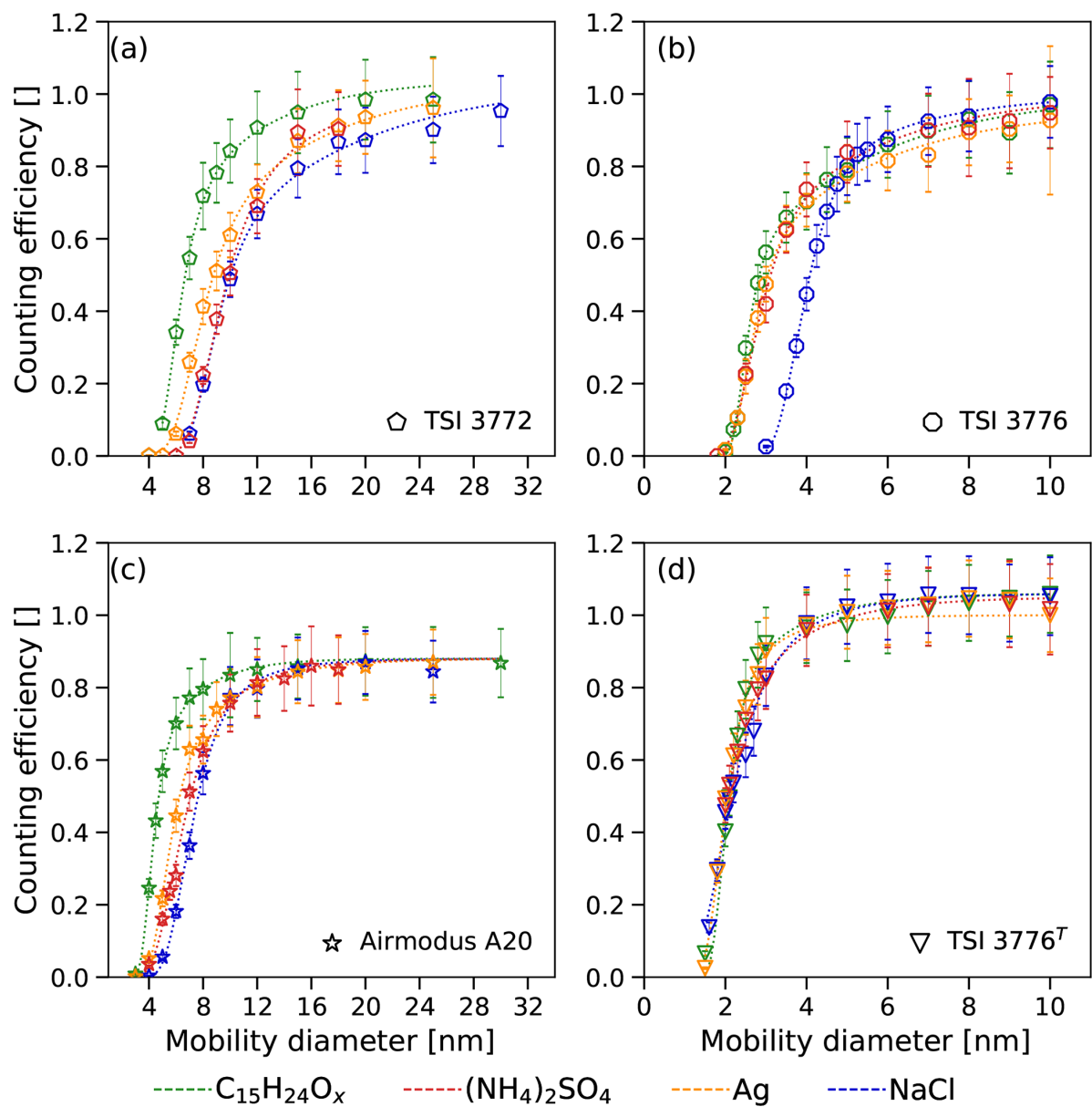

Figure 4. Detection efficiencies of the butanol-based CPCs: the figure shows the detection efficiencies as a function of the electrical mobility equivalent diameter. Every plot corresponds to a different butanol-based CPC: TSI 3772 (a), TSI 3776 (b), Airmodus A20 (c) and TSI $3776^{T}$ (d).

Table 2. Temperature settings: the table summarizes the standard temperature settings according to the user manuals of the particle counters and the empirically derived tuned temperature settings (see also Brilke et al., 2020b).

\begin{tabular}{|c|c|c|c|c|c|c|}
\hline Instrument & $T_{\text {Condenser }}$ & $T_{\text {Saturator }}$ & $T_{\text {Optics }}$ & $T_{\text {Conditioner }}$ & $T_{\text {Initiator }}$ & $T_{\text {Cabinet }}$ \\
\hline \multicolumn{7}{|c|}{ Standard $T$ settings $\left({ }^{\circ} \mathrm{C}\right)$} \\
\hline TSI 3776 & 10.0 & 39.0 & 40.0 & - & - & - \\
\hline TSI 3789 & - & - & 40.0 & 7.0 & 90.0 & 15.0 \\
\hline TSI 3777 & 12.0 & 62.0 & - & - & - & - \\
\hline \multicolumn{7}{|c|}{ Tuned $T$ settings $\left({ }^{\circ} \mathrm{C}\right)$} \\
\hline TSI $3776^{T}$ & 1.1 & 33.1 & 34.1 & - & - & - \\
\hline TSI $3789^{T}$ & - & - & 40.0 & 2.0 & 95.0 & 23.0 \\
\hline TSI $3777^{T}$ & 12.0 & 68.0 & - & - & - & - \\
\hline
\end{tabular}

that the less polar $\mathrm{BCYO}_{x}$ and $\mathrm{Ag}$ particles interact more strongly with the nonpolar $n$-butanol. These chemical similarities of the seed and working fluid are indeed reflected in the counting efficiencies: the $50 \%$ cutoff diameters of the ionic seeds are smaller when measured with the TSI 3789 or TSI 3777. On the other hand, the $50 \%$ cutoff diameters of $\mathrm{Ag}$ and $\mathrm{BCYO}_{x}$ seeds are smaller when measured with a butanol-based CPC (see Figs. 2-4). This different activation behavior also requires different theoretical approaches: while particle activation of two soluble compounds can be 


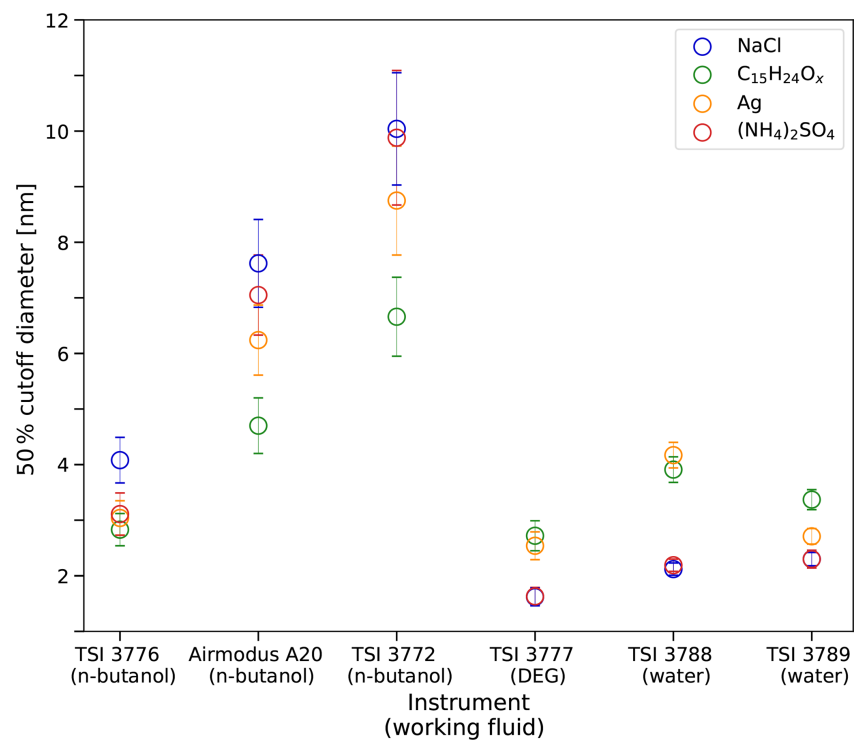

Figure 5. The $50 \%$ cutoff diameters for different working fluids: the figure shows the $50 \%$ cutoff diameters measured with the TSI 3776, Airmodus A20, TSI 3772, TSI 3777, TSI 3788 and TSI 3789. Different colors correspond to different seed particle compositions.

described by Köhler theory (Köhler, 1936), the Fletcher theory of heterogeneous nucleation (Fletcher, 1958) needs to be applied when the seed particle is not entirely soluble in the working fluid (Giechaskiel et al., 2011).

Additionally, the detection efficiency of the instruments is influenced by technical factors. The TSI 3776 and the TSI 3777 are based on a capillary-sheath layout. As a result, particle losses due to diffusion are smaller and the detection efficiencies reach higher values at smaller diameters compared to the TSI 3789 (see Fig. 2). Additionally, the detection efficiency curves become steeper.

By changing the temperature settings, higher peak saturation ratios are achieved, leading to smaller $50 \%$ cutoff diameters (see Fig. 6). The chosen settings increase the temperature difference between the cooled and heated regions inside the instruments, while simultaneously avoiding significant homogeneous nucleation. Homogeneous nucleation inside the instrument is tested by connecting a total particle filter to the inlet and verifying that no signal is detected. As shown by Tauber et al. (2019b), lowering the operating temperatures of a TSI 3776 by keeping the temperature difference between the saturator and condenser constant leads to an elevated saturation ratio profile in the condenser tube.

Furthermore, the interpretation of the results of seed particles with diameters $<2 \mathrm{~nm}$ is restricted to the knowledge of the exact composition of the seed particle material and cannot be extended to the composition of the produced aerosol particles. Previous research has shown that the use of tube furnaces and aerosol chargers based on radioactivity causes
Table 3. Summarized $50 \%$ cutoff diameters: the table shows the measured $50 \%$ cutoff diameters for the four different seed particle materials and for every particle counter in use.

\begin{tabular}{|c|c|c|c|c|}
\hline Seed & $\begin{array}{l}\text { Working } \\
\text { fluid }\end{array}$ & Instrument & $\begin{array}{r}d_{\mathrm{p}, 50} \\
(\mathrm{~nm})\end{array}$ & $\begin{array}{c}\Delta d_{\mathrm{p}, 50} \\
(\mathrm{~nm})\end{array}$ \\
\hline \multirow[t]{7}{*}{$\mathrm{NaCl}$} & \multirow[t]{4}{*}{$n$-butanol } & TSI 3776 & 4.0 & 0.4 \\
\hline & & TSI $3776^{T}$ & 2.2 & 0.2 \\
\hline & & TSI 3772 & 10.0 & 1.0 \\
\hline & & A 20 & 7.6 & 0.8 \\
\hline & \multirow[t]{2}{*}{ water } & TSI 3788 & 2.1 & 0.1 \\
\hline & & TSI 3789 & 2.3 & 0.1 \\
\hline & DEG & TSI 3777 & 1.6 & 0.3 \\
\hline \multirow[t]{7}{*}{$\mathrm{Ag}$} & \multirow[t]{4}{*}{$n$-butanol } & TSI 3776 & 3.0 & 0.3 \\
\hline & & TSI $3776^{T}$ & 2.0 & 0.2 \\
\hline & & TSI 3772 & 8.8 & 1.0 \\
\hline & & A20 & 6.2 & 0.6 \\
\hline & \multirow[t]{2}{*}{ water } & TSI 3788 & 4.2 & 0.2 \\
\hline & & TSI 3789 & 2.7 & 0.1 \\
\hline & DEG & TSI 3777 & 2.5 & 0.3 \\
\hline \multirow[t]{7}{*}{$\left(\mathrm{NH}_{4}\right)_{2} \mathrm{SO}_{4}$} & \multirow[t]{4}{*}{$n$-butanol } & TSI 3776 & 3.1 & 0.4 \\
\hline & & TSI $3776^{T}$ & 2.0 & 0.2 \\
\hline & & TSI 3772 & 9.9 & 1.2 \\
\hline & & A20 & 7.1 & 0.7 \\
\hline & \multirow[t]{2}{*}{ water } & TSI 3788 & 2.2 & 0.1 \\
\hline & & TSI 3789 & 2.3 & 0.2 \\
\hline & DEG & TSI 3777 & 1.6 & 0.3 \\
\hline \multirow[t]{9}{*}{$\mathrm{C}_{15} \mathrm{H}_{24} \mathrm{O}_{x}$} & \multirow[t]{4}{*}{$n$-butanol } & TSI 3776 & 2.8 & 0.3 \\
\hline & & TSI $3776^{T}$ & 2.1 & 0.2 \\
\hline & & TSI 3772 & 6.7 & 0.7 \\
\hline & & A20 & 4.7 & 0.5 \\
\hline & \multirow[t]{3}{*}{ water } & TSI 3788 & 3.9 & 0.2 \\
\hline & & TSI 3789 & 3.4 & 0.2 \\
\hline & & TSI $3789^{T}$ & 3.1 & 0.2 \\
\hline & \multirow[t]{2}{*}{ DEG } & TSI 3777 & 2.7 & 0.3 \\
\hline & & TSI $3777^{T}$ & 2.3 & 0.3 \\
\hline
\end{tabular}

impurities in the produced aerosol particles (Steiner et al., 2014; Maißer et al., 2015).

Tauber et al. (2019a) presented results of detection efficiency measurements from the TSI 3776 using $\mathrm{Ag}$ and $\mathrm{NaCl}$ seeds. Our results for $\mathrm{Ag}$ and $\mathrm{NaCl}$ are in perfect agreement with the results for a dry aerosol flow of Tauber et al. (2019a). As Brilke et al. (2020b) highlight, there is no composition dependence of the detection efficiencies of the TSI $3776^{T}$. The $50 \%$ cutoff diameters for negatively charged Ag seeds presented by the authors are also confirmed by our measurements. We report the same $50 \%$ cutoff diameters for the TSI $3776^{T}$ and $\left(\mathrm{NH}_{4}\right)_{2} \mathrm{SO}_{4}$ as reported by Kangasluoma et al. (2016), who also used a tuned TSI 3776 . We con- 

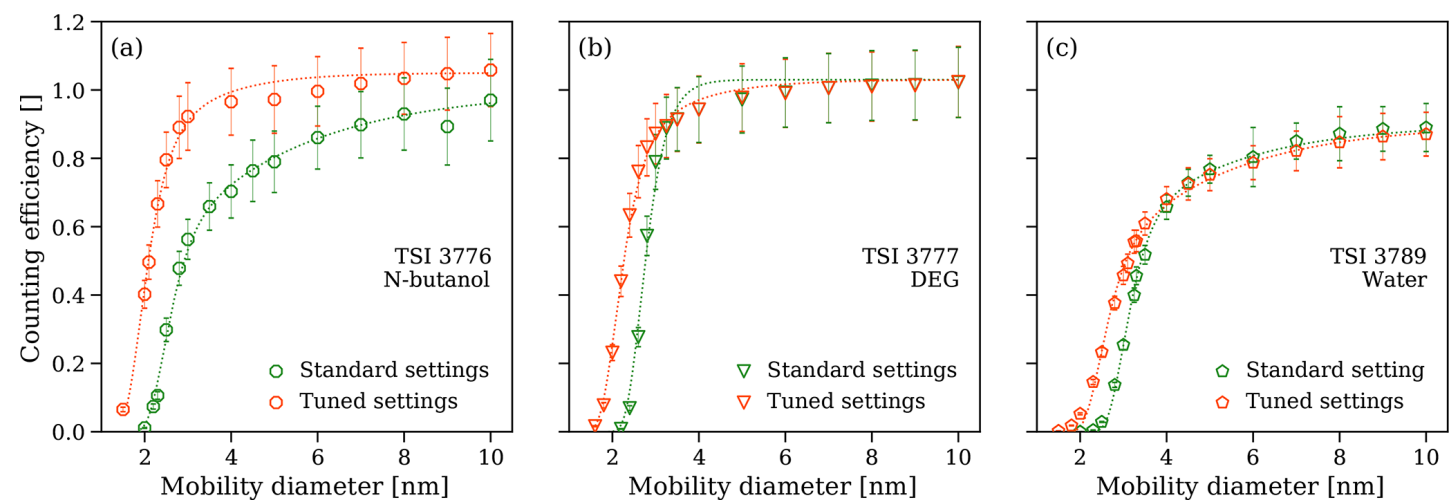

Figure 6. Detection efficiencies of the tuned instruments: the figure shows the detection efficiencies for $\mathrm{BCYO}_{x}$ seeds as a function of the electrical mobility equivalent diameter. The green lines correspond to the standard settings, and the orange lines correspond to the tuned settings. Every plot shows data from a different instrument: TSI 3776 (a), TSI 3777 (b) and TSI 3789 (c).

firm that the discussed trend of smaller $50 \%$ cutoff diameters when using CPCs based on water and DEG (with DEG being linked to the smallest one) is backed by our results. Kupc et al. (2013a) performed a laboratory characterization of the TSI 3788 and compared the results to the TSI 3776. The seed particles used also include negatively charged $\mathrm{NaCl}$ seeds. The $50 \%$ cutoff diameters for positively charged $\mathrm{NaCl}$ measured with the TSI 3788 are in good agreement, but we report distinctly larger $50 \%$ cutoff diameters for positively charged $\mathrm{NaCl}$ measured with the TSI 3776. In their publication about DEG-based particle counters, Wimmer et al. (2013) present $50 \%$ cutoff diameters for negatively charged $\left(\mathrm{NH}_{4}\right)_{2} \mathrm{SO}_{4}$ seeds. The results of our study also support these measurements.

\subsection{Supersaturation profiles}

To confirm our measurement results regarding the cutoff diameters with theoretical calculations, we simulated the maximum supersaturations for the three butanol-based CPCs (TSI 3776, TSI $3776^{T}$ and TSI 3772). The supersaturations in the Airmodus A20 were provided by the manufacturer. Measurements of neutral $\mathrm{Ag}$ seeds performed with a size analyzing nuclei counter (SANC; Tauber et al., 2019a; Wagner, 1985) were used to correctly simulate the maximum supersaturation that seed particles were exposed to (Tauber et al., 2019b). Therefore, we evaluated the heat and mass transfer for a fully developed laminar flow with no mixing according to Stolzenburg and McMurry (1991). The original geometry was transformed to a circular tube to solve the equations with constant boundary conditions (constant temperatures; Eckert and Drake, 1972). For the flow a parabolic velocity flow profile was considered and used to simulate the convective-diffusive heat and mass transfer for the simulation domain following Tauber et al. (2019b). The results are presented in Table 4, showing the calculated corresponding minimum diameters that can be activated. The highest supersaturations $\left(S_{\max }=4.61\right)$ are reached in the TSI $3776^{T}$, and
Table 4. Calculated supersaturation ratios: the table shows the results of the modeling of the supersaturation profiles of four different particle counters. The maximum supersaturation ratio is related to the smallest particle diameter necessary for the activation of neutral silver seeds.

\begin{tabular}{lcc}
\hline Instrument & $S_{\max }$ & $\begin{array}{l}d_{\mathrm{p}, 0} \\
(\mathrm{~nm})\end{array}$ \\
\hline TSI 3776 & 3.43 & 2.20 \\
TSI 3776 & 4.61 & 1.80 \\
TSI 3772 & 1.68 & 5.40 \\
Airmodus A20 & 1.93 & 4.20 \\
\hline
\end{tabular}

particles are exposed to the lowest supersaturations in the TSI $3772\left(S_{\max }=1.93\right)$, as expected according to our calculations.

We correlated the measured $5 \%$ cutoff diameter with the diameters that can be theoretically activated $\left(d_{\mathrm{p}, 0}^{T}\right)$. The comparison was done for silver particles. In the theoretical calculations neutral particles were used, whereas in the case of the measurements we used negatively charged silver particles. Figure 7 shows a remarkable correlation between the theory and the measurements, resulting in an $R^{2}$ of 0.98 . In the case of the smallest diameter, the calculated diameter is $1.8 \mathrm{~nm}$ and the measured one is $1.5 \pm 0.2 \mathrm{~nm}$. This deviation is most likely due to the charge effect (Tauber et al., 2018). We are therefore able to correctly predict the onset of detection in CPCs from simulated supersaturation profiles; this implies that we can infer the maximum supersaturation inside the condenser for specific CPCs, which was generally unknown for most CPCs so far. Calculated supersaturation profiles can be found in the Supplement (see Figs. S6 and S7). 


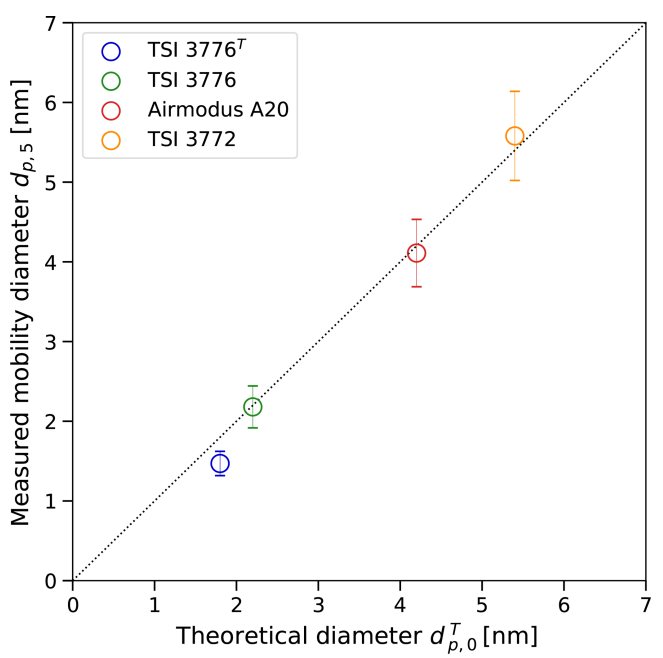

Figure 7. Theoretical diameters: the figure shows the theoretically minimal diameters necessary for particle activation of neutral silver seeds as a function of the measured $5 \%$ cutoff diameter for negatively charged silver seeds. Every color corresponds to a different particle counter. Data points on the dashed line stand for the equality of the theoretical and measured diameters.

\section{Conclusions}

The effect of the chemical composition of seed particles on the detection efficiency in commonly used CPCs based on different working fluids was investigated. These characterizations included organic seed particles that were generated in a controlled way. We present the first characterization measurements of the newly developed TSI 3789 using seed particles with diameters between 1 and $25 \mathrm{~nm}$. Furthermore, the onset of detection in CPCs was successfully and correctly predicted based on simulated supersaturation profiles.

Chemical similarities between the seed particle material and the working fluids used have been found to have an impact on the detection efficiency of CPCs. It has been shown that shifts in the detection efficiencies also occur for CPCs with $50 \%$ cutoff diameters larger than $5 \mathrm{~nm}$. Additionally, it was confirmed that the detection efficiency can be improved by changing the temperature and flow rate settings of the instruments. Remarkably, the TSI 3776 also did not show any shifts in the detection efficiency for $\mathrm{NaCl},\left(\mathrm{NH}_{4}\right)_{2} \mathrm{SO}_{4}$ and $\mathrm{BCYO}_{x}$ seeds when operated using the tuned settings. This behavior is linked to the higher saturation ratio after tuning the CPC. The saturation ratio might be high enough that differences in the detection efficiencies of different seed particles no longer occur.

Consequently, we conclude that the $50 \%$ cutoff diameter as the sole parameter is not sufficient to characterize the detection efficiency of a CPC. Shifts of the detection efficiency and curve shapes are influenced by the aforementioned interactions. We recommend that CPC characterizations be performed using various polar and less polar seed particles, in- cluding $\mathrm{Ag}$ seeds, in order to correctly present the detection efficiency of a CPC. The chemical composition of the measured aerosol particles should be considered when instruments are calibrated. The authors recommend following the calibration standard based on Ag seeds, introduced by Wiedensohler et al. (2018), when a variety of seed particle materials is not at hand. In the future, measurements of the activation efficiency with $\mathrm{Ag}$ could then be used to infer the achieved supersaturation in the CPC. Subsequent comparisons to further SANC measurements with other seed materials (e.g., NaCl; Tauber et al., 2019b) then allow researchers to infer the corresponding counting efficiencies. Future research needs to focus on the extension and verification of the presented results for sub- $2 \mathrm{~nm}$ particles with known composition. Hence, the presented study suggests a novel and improved approach to determining the counting efficiencies of CPCs when a calibration with a variety of seed particles is not available.

Data availability. Raw data are available upon request from the authors.

Supplement. The supplement related to this article is available online at: https://doi.org/10.5194/amt-13-3787-2020-supplement.

Author contributions. DW, SHS and PMW presented the idea. PJW, DS, SB and DW designed the setup and performed the measurements. CT calculated the supersaturation profiles for the TSI CPCs. PJW, DS, CT and DW analyzed the data. PJW, DS, CT, SB, SHS, PMW and DW were involved in the scientific interpretation of the results. PJW, DS, SB and DW wrote the paper. All authors participated in reviewing the paper.

Competing interests. The authors declare that they have no conflict of interest. This study was independently performed and was not co-funded by TSI Inc. and Airmodus Ltd.

Acknowledgements. The authors thank TSI Inc. for kindly providing a TSI 3789 for the measurements. Furthermore, the authors acknowledge Axel Zerrath for providing technical support concerning the newly developed TSI 3789. Joonas Enroth is acknowledged for calculating the supersaturation profile of the Airmodus A20 and providing it to the authors.

Financial support. This research has been supported by the Austrian Science Fund (FWF) (project no. J3951-N36) and the European Research Council (grant no. 616075).

Review statement. This paper was edited by Pierre Herckes and reviewed by three anonymous referees. 


\section{References}

Ahonen, L. R., Kangasluoma, J., Lammi, J., Lehtipalo, K., Hämeri, K., Petäjä, T., and Kulmala, M.: First measurements of the number size distribution of 1-2 nm aerosol particles released from manufacturing processes in a cleanroom environment, Aerosol Sci. Tech., 51, 685-693, https://doi.org/10.1080/02786826.2017.1292347, 2017.

Aitken, J.: On the number of dust particles in the atmosphere, T. Roy. Soc. Edin.-Earth, 35, 1-19, 1888.

Albrecht, B. A.: Aerosols, Cloud Microphysics, and Fractional Cloudiness, Science, 245, 1227-1230, https://doi.org/10.1126/science.245.4923.1227, 1989.

Attoui, M.: Activation of sub $2 \mathrm{~nm}$ singly charged particles with butanol vapors in a boosted 3776 TSI CPC, J. Aerosol Sci., 126, 47-57, https://doi.org/10.1016/j.jaerosci.2018.08.005, 2018.

Attoui, M. and Kangasluoma, J.: Activation of sub $2 \mathrm{~nm}$ Water Soluble and Insoluble Standard Ions with Saturated Vapors of Butanol in a Boosted TSI ultrafine CPC, Atmosphere, 10, 655, https://doi.org/10.3390/atmos10110665, 2019.

Barmpounis, K., Ranjithkumar, A., Schmidt-Ott, A., Attoui, M., and Biskos, G.: Enhancing the Detection Efficiency of Condensation Particle Counters for Sub-2 nm Particles, J. Aerosol Sci., 117, 44-53, https://doi.org/10.1016/j.jaerosci.2017.12.005, 2017.

Bauer, S. E. and Menon, S.: Aerosol direct, indirect, semidirect, and surface albedo effects from sector contributions based on the IPCC AR5 emissions for preindustrial and present-day conditions, J. Geophys. Res., 117, D01206, https://doi.org/10.1029/2011JD016816, 2012.

Brilke, S., Fölker, N., Müller, T., Kandler, K., Gong, X., Peischl, J., Weinzierl, B., and Winkler, P. M.: New particle formation and sub-10 $\mathrm{nm}$ size distribution measurements during the A-LIFE field experiment in Paphos, Cyprus, Atmos. Chem. Phys., 20, 5645-5656, https://doi.org/10.5194/acp-20-5645-2020, 2020a.

Brilke, S., Resch, J., Leiminger, M., Steiner, G., Tauber, C., Wlasits, P. J., and Winkler, P. M.: Precision characterization of three ultrafine condensation particle counters using mobility standards in the $1-4 \mathrm{~nm}$ size range generated by a bipolar electrospray source, Aerosol Sci. Technol., 54, 396-409, https://doi.org/10.1080/02786826.2019.1708260, 2020b.

Eckert, E. and Drake, R.: Analysis of Heat and Mass Transfer, McGraw-Hill Book Co., New York, 1972.

Flagan, R. C.: On Differential Mobility Analyzer Resolution, Aerosol Sci. Tech., 30, 556-570, https://doi.org/10.1080/027868299304417, 1999.

Fletcher, N. H.: Size Effect in Heterogeneous Nucleation, J. Chem. Phys., 29, 572-576, https://doi.org/10.1063/1.1744540, 1958.

Gamero-Castaño, M. and Fernández de la Mora, J.: A condensation nucleus counter (CNC) sensitive to singly charged sub-nanometer particles, J. Aerosol Sci., 31, 757-772, https://doi.org/10.1016/S0021-8502(99)00555-8, 2000.

Gao, X., Zou, H., Xu, X., Zhou, L., Tang, S., Yuan, W., and Zhang, M.: Developing a guideline for measuring the total number concentration of engineering nanomaterials in workplaces in China, J. Occup. Health, 61, 197-202, https://doi.org/10.1002/13489585.12044, 2019.

Giechaskiel, B., Wang, X., Horn, H.-G., Spielvogel, J., Gerhart, C., Southgate, J., Jing, L., Kasper, M., Drossinos, Y., and Krasenbrink, A.: Calibration of Condensation Particle Counters for Legislated Vehicle Number Emis- sion Measurements, Aerosol Sci. Tech., 43, 1164-1173, https://doi.org/10.1080/02786820903242029, 2009.

Giechaskiel, B., Wang, X., Gilliland, D., and Drossinos, Y.: The effect of particle chemical composition on the activation probability in n-butanol condensation particle counters, J. Aerosol Sci., 42, 20-37, https://doi.org/10.1016/j.jaerosci.2010.10.006, 2011.

Gormley, P. G. and Kennedy, M.: Diffusion from a Stream Flowing through a Cylindrical Tube, P. Roy. Irish Acad. A, 52, 163-169, 1948.

Hearn, J. D. and Smith, G. D.: A mixed-phase relative rates technique for measuring aerosol reaction kinetics, Geophys. Res. Lett., 33, L17805, https://doi.org/10.1029/2006GL026963, 2006.

Hering, S. V., Stolzenburg, M. R., Quant, F. R., Oberreit, D. R., and Keady, P. B.: A Laminar-Flow, Water-Based Condensation Particle Counter (WCPC), Aerosol Sci. Tech., 39, 659-672, https://doi.org/10.1080/02786820500182123, 2005.

Hering, S. V., Lewis, G. S., Spielman, S. R., Eiguren-Fernandez, A., Kreisberg, N. M., Kuang, C., and Attoui, M.: Detection near 1-nm with a laminar-flow, water-based condensation particle counter, Aerosol Sci. Tech., 51, 354-362, https://doi.org/10.1080/02786826.2016.1262531, 2017.

Hering, S. V., Lewis, G. S., Spielman, S. R., and EigurenFernandez, A.: A MAGIC concept for self-sustained, waterbased, ultrafine particle counting, Aerosol Sci. Tech., 53, 63-72, https://doi.org/10.1080/02786826.2018.1538549, 2019.

Iida, K., Stolzenburg, M., and McMurry, P.: Effect of Working Fluid on Sub-2 nm Particle Detection with a Laminar Flow Ultrafine Condensation Particle Counter, Aerosol Sci. Tech., 43, 81-96, https://doi.org/10.1080/02786820802488194, 2009.

Jiang, J., Attoui, M., Heim, M., Brunelli, N. A., McMurry, P. H., Kasper, G., Flagan, R. C., Giapis, K., and Mouret, G.: Transfer Functions and Penetrations of Five Differential Mobility Analyzers for Sub-2 nm Particle Classification, Aerosol Sci. Tech., 45, 480-492, https://doi.org/10.1080/02786826.2010.546819, 2011.

Kangasluoma, J. and Attoui, M.: Review of sub-3 nm condensation particle counters, calibrations and cluster generation methods, Aerosol Sci. Tech., 53, 1277-1310, https://doi.org/10.1080/02786826.2019.1654084, 2019.

Kangasluoma, J., Junninen, H., Lehtipalo, K., Mikkilä, J., Vanhanen, J., Attoui, M., Sipilä, M., Worsnop, D., Kulmala, M., and Petäjä, T.: Remarks on Ion Generation for CPC Detection Efficiency Studies in Sub-3 nm Size Range, Aerosol Sci. Tech., 47, 556-563, https://doi.org/10.1080/02786826.2013.773393, 2013.

Kangasluoma, J., Kuang, C., Wimmer, D., Rissanen, M. P., Lehtipalo, K., Ehn, M., Worsnop, D. R., Wang, J., Kulmala, M., and Petäjä, T.: Sub-3 nm particle size and composition dependent response of a nano-CPC battery, Atmos. Meas. Tech., 7, 689-700, https://doi.org/10.5194/amt-7-689-2014, 2014.

Kangasluoma, J., Samodurov, A., Attoui, M., Franchin, A., Junninen, H., Korhonen, F., Kurtén, T., Vehkamäki, H., Sipilä, M., Lehtipalo, K., Worsnop, D. R., Petäjä, T., and Kulmala, M.: Heterogeneous Nucleation onto Ions and Neutralized Ions: Insights into Sign-Preference, J. Phys. Chem. C, 120, 7444-7450, https://doi.org/10.1021/acs.jpcc.6b01779, 2016.

Kulmala, M., Mordas, G., Petäjä, T., Grönholm, T., Aalto, P. P., Vehkamäki, H., Hienola, A. I., Herrmann, E., Sipilä, M., Riipinen, I., Manninen, H. E., Hämeri, K., Stratmann, F., Bilde, M., Winkler, P. M., Birmili, W., and Wagner, P. E.: The condensation particle counter battery (CPCB): A new tool to investigate the ac- 
tivation properties of nanoparticles, J. Aerosol Sci., 38, 289-304, https://doi.org/10.1016/j.jaerosci.2006.11.008, 2007.

Kupc, A., Bischof, O., Tritscher, T., Beeston, M., Krinke, T., and Wagner, P. E.: Laboratory Characterization of a New NanoWater-Based CPC 3788 and Performance Comparison to an U1trafine Butanol-Based CPC 3776, Aerosol Sci. Tech., 47, 183191, https://doi.org/10.1080/02786826.2012.738317, 2013a.

Kupc, A., Winkler, P. M., Vrtala, A., and Wagner, P.: Unusual Temperature Dependence of Heterogeneous Nucleation of Water Vapor on Ag Particles, Aerosol Sci. Tech., 47, i-iv, https://doi.org/10.1080/02786826.2013.810330, 2013b.

Köhler, H.: The nucleus in and the growth of hygroscopic droplets, T. Faraday Soc., 32, 1152-1161, https://doi.org/10.1039/TF9363201152, 1936.

Li, C. and Hogan Jr., C. J.: Vapor specific extents of uptake by nanometer scale charged particles, Aerosol Sci. Tech., 51, 653664, https://doi.org/10.1080/02786826.2017.1288285, 2017.

Magnusson, L.-E., Koropchak, J., Anisimov, M., M Poznjakovskiy, V., and Fernandez de la Mora, J.: Correlations for Vapor Nucleating Critical Embryo Parameters, J. Phys. Chem. Ref. Data, 32, 1387-1409, https://doi.org/10.1063/1.1555590, 2003.

Maißer, A., Thomas, J. M., Larriba-Andaluz, C., He, S., and Hogan, C. J.: The mass-mobility distributions of ions produced by a Po-210 source in air, J. Aerosol Sci., 90, 36-50, https://doi.org/10.1016/j.jaerosci.2015.08.004, 2015.

McMurry, P. H.: The History of Condensation Nucleus Counters, Aerosol Sci. Tech., 33, 297-322, https://doi.org/10.1080/02786820050121512, 2000.

Nieminen, T., Kerminen, V.-M., Petäjä, T., Aalto, P. P., Arshinov, M., Asmi, E., Baltensperger, U., Beddows, D. C. S., Beukes, J. P., Collins, D., Ding, A., Harrison, R. M., Henzing, B., Hooda, R., Hu, M., Hõrrak, U., Kivekäs, N., Komsaare, K., Krejci, R., Kristensson, A., Laakso, L., Laaksonen, A., Leaitch, W. R., Lihavainen, H., Mihalopoulos, N., Németh, Z., Nie, W., O’Dowd, C., Salma, I., Sellegri, K., Svenningsson, B., Swietlicki, E., Tunved, P., Ulevicius, V., Vakkari, V., Vana, M., Wiedensohler, A., Wu, Z., Virtanen, A., and Kulmala, M.: Global analysis of continental boundary layer new particle formation based on longterm measurements, Atmos. Chem. Phys., 18, 14737-14756, https://doi.org/10.5194/acp-18-14737-2018, 2018.

Pedata, P., Stoeger, T., Zimmermann, R., Peters, A., Oberdörster, G., and D'Anna, A.: "Are we forgetting the smallest, sub $10 \mathrm{~nm}$ combustion generated particles?", Part. Fibre Toxicol., 12, 34, https://doi.org/10.1186/s12989-015-0107-3, 2015.

Petäjä, T., Mordas, G., Manninen, H., Aalto, P. P., Hämeri, K., and Kulmala, M.: Detection Efficiency of a Water-Based TSI Condensation Particle Counter 3785, Aerosol Sci. Tech., 40, 10901097, https://doi.org/10.1080/02786820600979139, 2006.

Reischl, G. P., Mäkelä, J. M., and Necid, J.: Performance of Vienna Type Differential Mobility Analyzer at 1.2-20 Nanometer, Aerosol Sci. Tech., 27, 651-672, https://doi.org/10.1080/02786829708965503, 1997.

Scheibel, H. and Porstendorfer, J.: Generation of monodisperse $\mathrm{Ag}-$ and $\mathrm{NaCl}$-aerosols with particle diameters between 2 and $300 \mathrm{~nm}$, J. Aerosol Sci., 14, 113-126, https://doi.org/10.1016/0021-8502(83)90035-6, 1983.

Seto, T., Okuyama, K., de Juan, L., and Fernández de la Mora, J.: Condensation of supersaturated vapors on monovalent and di- valent ions of varying size, J. Chem. Phys., 107, 1576-1585, https://doi.org/10.1063/1.474510, 1997.

Sgro, L. A. and Fernández de la Mora, J.: A Simple Turbulent Mixing CNC for Charged Particle Detection Down to $1.2 \mathrm{~nm}$, Aerosol Sci. Tech., 38, 1-11, https://www.tandfonline.com/doi/ full/10.1080/02786820490247560, 2004.

Steiner, G., Attoui, M., Wimmer, D., and Reischl, G. P.: A Medium Flow, High-Resolution Vienna DMA Running in Recirculating Mode, Aerosol Sci. Tech., 44, 308-315, https://doi.org/10.1080/02786821003636763, 2010.

Steiner, G., Jokinen, T., Junninen, H., Sipilä, M., Petäjä, T., Worsnop, D., Reischl, G. P., and Kulmala, M.: High-Resolution Mobility and Mass Spectrometry of Negative Ions Produced in a ${ }^{241} \mathrm{Am}$ Aerosol Charger, Aerosol Sci. Tech., 48, 261-270, https://doi.org/10.1080/02786826.2013.870327, 2014.

Stolzenburg, M. R. and McMurry, P. H.: An Ultrafine Aerosol Condensation Nucleus Counter, Aerosol Sci. Tech., 14, 48-65, https://doi.org/10.1080/02786829108959470, 1991.

Tauber, C., Chen, X., E Wagner, P., M Winkler, P., Hogan, C., and Maisser, A.: Heterogeneous Nucleation onto Monoatomic Ions: Support for the Kelvin-Thomson Theory, ChemPhysChem, 19, 3144, https://doi.org/10.1002/cphc.201800698, 2018.

Tauber, C., Brilke, S., Wlasits, P. J., Bauer, P. S., Köberl, G., Steiner, G., and Winkler, P. M.: Humidity effects on the detection of soluble and insoluble nanoparticles in butanol operated condensation particle counters, Atmos. Meas. Tech., 12, 3659-3671, https://doi.org/10.5194/amt-12-3659-2019, 2019a.

Tauber, C., Steiner, G., and Winkler, P. M.: Counting efficiency determination from quantitative intercomparison between expansion and laminar flow type condensation particle counter, Aerosol Sci. Tech., 53, 344-354, https://doi.org/10.1080/02786826.2019.1568382, 2019b.

Vanhanen, J., Mikkilä, J., Lehtipalo, K., Sipilä, M., Manninen, H. E., Siivola, E., Petäjä, T., and Kulmala, M.: Particle Size Magnifier for Nano-CN Detection, Aerosol Sci. Tech., 45, 533-542, https://doi.org/10.1080/02786826.2010.547889, 2011.

Wagner, P. E.: A Constant-Angle Mie Scattering Method (CAMS) for Investigation of Particle Formation Processes, J. Colloid Interf. Sci., 105, 456-467, https://doi.org/10.1016/00219797(85)90319-4, 1985.

Wiedensohler, A., Wiesner, A., Weinhold, K., Birmili, W., Hermann, M., Merkel, M., Müller, T., Pfeifer, S., Schmidt, A., Tuch, T., Velarde, F., Quincey, P., Seeger, S., and Nowak, A.: Mobility particle size spectrometers: Calibration procedures and measurement uncertainties, Aerosol Sci. Tech., 52, 146-164, https://doi.org/10.1080/02786826.2017.1387229, 2018.

Wimmer, D., Lehtipalo, K., Franchin, A., Kangasluoma, J., Kreissl, F., Kürten, A., Kupc, A., Metzger, A., Mikkilä, J., Petäjä, T., Riccobono, F., Vanhanen, J., Kulmala, M., and Curtius, J.: Performance of diethylene glycol-based particle counters in the sub-3 nm size range, Atmos. Meas. Tech., 6, 1793-1804, https://doi.org/10.5194/amt-6-1793-2013, 2013.

Winkler, P. M., Steiner, G., Vrtala, A., Vehkamäki, H., Noppel, M., Lehtinen, K. E. J., Reischl, G. P., Wagner, P. E., and Kulmala, M.: Heterogeneous Nucleation Experiments Bridging the Scale from Molecular Ion Clusters to Nanoparticles, Science, 319, 1374 1377, https://doi.org/10.1126/science.1149034, 2008. 